\title{
DEMOCRACIA EM AS DUAS FONTES DA MORAL E DA RELIGIÃO: RESISTÊNCIA E ASPIRAÇÃO
}

\author{
Maria Adriana Camargo Cappello ${ }^{1}$
}

\begin{abstract}
Resumo: O presente artigo tem por objetivo refletir sobre a concepção de democracia, apresentada por Bergson, em As duas fontes da moral e da religiäo, enquanto movimento humano e social de resistência e de aspiração, no contexto de uma teoria da vida concebida, ela própria, como um movimento que se dá em dois sentidos, o da determinação e o da criação.
\end{abstract}

Palavras-Chave: Bergson. Moral. Política. Democracia. Evolução. Criação. Determinação.

Nosso objetivo, aqui, é o de uma primeira aproximação da concepção de democracia, apresentada por Bergson, em sua última obra, As duas fontes da moral e da religiáo,(BERGSON, 2008a) a partir da própria intenção por ele explicitada, ao concluir as poucas páginas dedicadas ao tema, a saber, "[...] ter mostrado no estado de alma democrático um grande esforço em sentido inverso ao da natureza."(BERGSON, 2008a, p. 302). Como essas palavras já deixam entrever, a concepção de democracia trazida por Bergson diz mais respeito a uma investigação sobre a alma humana, no contexto da socialização, do que a uma investigação sobre a constituição de um regime de Estado. Além disso, deixam entrever que tal concepção só ganha sentido no âmbito de uma investigação maior, o de uma teoria da vida - entendida como uma teoria da natureza geradora de "naturezas" -, na qual o homem, em sua organização em sociedade, está concernido.

No entanto, segundo a hipótese que desejamos explorar, o esforço da alma humana para desenvolver-se no sentido da democracia - esforço que, de resto, só pode ocorrer na vida humana em sociedade - é inverso ao da natureza em um sentido bastante preciso, pelo qual "natureza", antes de poder ser

\footnotetext{
${ }^{1}$ Com formação acadêmica em Filosofia na Universidade de São Paulo, é professora do Departamento de Filosofia e do Programa de Pós-Graduação em Filosofia da UFPR, desde 2005. Desenvolve sua pesquisa e produção acadêmica na área da História da Filosofia Moderna e Contemporânea, atuando principalmente com os temas da temporalidade, consciência e liberdade segundo a abordagem crítica e metafísica proposta pela Filosofia de Bergson. E-mail: adrianacappello@uol.com.br
} http://dx.doi.org/10.1590/S0101-31732017000200008 
caracterizada em sua comum oposição à cultura, opóe-se a um outro sentido de "natureza" também reconhecido por Bergson. Com efeito, no contexto de sua teoria da vida, Bergson nos remete a dois sentidos de natureza - e, somente a partir destes, dois sentidos de cultura -; a saber, o sentido do movimento gerador de vida e o sentido da estabilidade das formas de vida então geradas (BERGSON, 2008b).

É assim que, segundo nossa leitura, se, para Bergson, a democracia é um esforço da alma humana que vai no sentido inverso ao da natureza, é justamente porque ela vai no sentido inverso àquele que caracteriza a espécie humana, entendendo-se "espécie" enquanto momento de estabilidade de um movimento gerador de formas de vida - com todas as determinaçóes características das formas de vida então geradas. Determinaçóes que, justamente, no que diz respeito à socialização da humanidade, fundam-se no sentimento de uma obrigação imposta por pressão. Mas, se a democracia é esse esforço do homem no sentido inverso a essa sua natureza social regida por esse sentimento de obrigação, se ela é um esforço do homem para fundar uma sociedade que transcenda a esse sentimento, isto se dá justamente porque ela é um esforço do homem em transcender-se a si mesmo, enquanto espécie, reinserindo-se nesse outro sentido de natureza, que é o do movimento de vida gerador de espécies. E será, portanto, nesse contexto de inversão do sentido de uma natureza determinada para o sentido de uma natureza que é fonte criadora de naturezas, que pensamos poder circunscrever a noção de democracia, em Bergson, como a de um movimento do homem em sociedade que tanto resiste às determinaçóes naturais a essa sociedade quanto aspira à criação de uma nova sociedade, um movimento, portanto, de resistência e de aspiração.

Para melhor compreendermos esses dois sentidos partindo, inicialmente, da dualidade presente na natureza, podemos recorrer à aproximaçáo que o próprio Bergson faz entre o seu pensamento e o de Espinosa, ao cotejar a dualidade que ele, Bergson, vê na natureza, àquela expressa por Espinosa entre "natureza naturada" e "natureza naturanda". Grossissimo modo, entre uma natureza que é, por um lado, origem, causa - nos termos de Bergson, movimento criador, gerador, impulso de vida, elã - e, por outro lado, suas manifestaçôes, ou seja, ainda nos termos de Bergson (2008a, p. 56), as próprias espécies vivas. Com efeito, essa concepção do duplo sentido da natureza que é longa e propriamente desenvolvida em seu livro anterior, Evoluçáo Criadora -, é retomada nas Duas Fontes, em um esforço de compreensão das implicaçóes, desses dois sentidos opostos, na organizaçáa dos indivíduos da 
espécie humana em sociedade, mais especificamente, na moral, na religião e nas formas de poder político nela estabelecidas.

De fato, Bergson não pensa a sociedade como uma organização exclusiva aos indivíduos da espécie humana. Sociedade, para ele, significa toda forma de coordenação ou subordinação firmada entre os indivíduos de qualquer espécie, no sentido de sua sobrevivência e perpetuação. "Humana ou animal" -, nos diz Bergson (2008a, p. 22), “[...] a sociedade é uma organização. Implica uma coordenação e, geralmente, também uma subordinação de elementos uns em relação aos outros; ela oferece, portanto, simplesmente vivida ou, além disso, representada, um conjunto de regras ou de leis." Formas específicas de coordenação ou de subordinação, que, no entanto, segundo a dualidade mesma dos sentidos da vida na qual foram geradas, guardam em si seu movimento gerador e, desse modo, a possibilidade de sua evolução. Em outras palavras, sociedade significa, para Bergson, uma organização, podemos dizer, em segundo grau, de organismos de uma determinada espécie; organizaçáo em segundo grau que, por sua vez, guarda as determinaçóes que caracterizam cada organismo particular que compóe a mesma espécie. Determinaçóes que, de resto, devem ser consideradas, se se quiser continuar na direção mesma do movimento gerador que as criou.

É assim, portanto, que, para Bergson, os dois sentidos da cultura humana, considerada nos diferentes aspectos inerentes à organização em sociedade - moral, jurídico, religioso e político -, estão intrinsecamente ligados aos dois sentidos de natureza, tanto enquanto reafirmação do movimento gerador como enquanto reafirmação dos modos de manifestação desse movimento criador, dos seus modos de parada, de seus estacionamentos momentâneos.

E é assim, ainda, que as consideraçóes de Bergson sobre a política propriamente dita, e sobre a democracia, em particular, só seráo desenvolvidas após os resultados obtidos, em todo o primeiro capítulo de As Duas Fontes, sobre o modo em que a organização própria aos indivíduos da espécie humana - a sociedade humana - sai das máos da natureza, ou seja, sai da forma mesma dada pela natureza a esses organismos e determina o que chamamos de moral. De fato, como já fora proposto em Evolução Criadora, para Bergson, a diferença fundamental entre os homens - animais predominantemente inteligentes - e os demais animais, predominantemente instintivos, seria dada por suas formas e funçôes biológicas, por seu organismo. De um lado, os animais predominantemente instintivos teriam no seu próprio corpo o 
instrumento para transformar o seu entorno, de sorte a conseguir seus meios de sobrevivência e reprodução, instrumentos perfeitamente adequados e, porém, restritos, nessa sua adequação, a apenas um modo de ação. De outro lado, a espécie humana, cujos indivíduos teriam sido dotados pela natureza com um corpo constituído menos como instrumento especializado para determinada ação e, mais, como instrumento capaz de fabricar instrumentos adequados para as variadas açóes pelas quais retirariam de seu entorno os meios para sua sobrevivência e reprodução. E seria justamente essa capacidade de adequar meios - instrumentos inventados - a fins, que caracterizaria, para Bergson, o que chamamos de inteligência humana. Capacidade de adequar meios a fins que pressupóe carência de especialização, mas perfectibilidade contínua. Pois, os instrumentos inventados pelo homem e que teriam, por isso mesmo, a característica de náo serem perfeitamente adequados para as açóes que se pode fazer por meio deles, podem, por outro lado, servir para múltiplas funçóes. Múltiplas funçôes que, por sua vez, implicam um arco de possibilidades e, consequentemente, de escolha. É assim que a própria configuração orgânica da espécie humana teria trazido consigo a potencialização da escolha e, com isso, um certo sentido de liberdade.

É preciso, portanto, compreender, no que diz respeito, especificamente, à organização humana em sociedade, de um lado, como a tendência da natureza à conservação das espécies se compóe com esse princípio de liberdade e, de outro, se esse princípio de liberdade não seria o próprio relançamento da tendência da natureza à criação.

Justamente o que parece fazer Bergson, quando procura compreender, no primeiro capítulo de As Duas Fontes, a formação, na espécie humana, de uma moral que, de uma parte, se explica por um sentimento de obrigaçáo - a moral fechada - e, de outra, por um sentimento de aspiração - a moral aberta -, constituindo o que ele chama de sociedades fechadas e de sociedades abertas. Busca compreender, por conseguinte, a formação de hábitos que harmonizariam a especificidade humana - sua inteligência e sua capacidade de escolha, princípio de liberdade - com as determinaçóes inerentes à organização em sociedade, com a obrigação; hábitos que fariam às vezes, no homem, da necessidade representada pelas formas e funçóes dos corpos nos animais. Ademais, compreender a possibilidade mesma de resistir a esses hábitos e ir, para além da sociedade, no sentido do que Bergson chama de suprassocial. 


\section{OBRIGAÇÁO MORAL E NECESSIDADE NATURAL}

De fato, as primeiras palavras de As Duas Fontes da Moral e da Religião, nas quais se concretiza a inserção profunda do social em nós ou, poderíamos dizer, a faceta social de nossa constituição, chamam, no modo da interdição, pela noção de obrigação. "A lembrança do fruto proibido é o que há de mais antigo na memória de cada um de nós, assim como na da humanidade.”( BERGSON, 2008a, p. 1). Sentimo-nos obrigados em relação a determinados comportamentos - sobretudo, em relação à interdição de certos comportamentos - e pressentimos, desde cedo, que as obrigaçóes que se impóem a cada um de nós, pela autoridade daqueles que nos são mais próximos (nossos pais, nossos professores), remetem a uma autoridade que está para além deles. "Para além de nossos pais e de nossos professores adivinhamos algo de muito maior ou, sobretudo, de indefinido que, por intermédio deles, se abate sobre nós com todo o seu peso." (BERGSON, 2008a, p. 1). Mais tarde, chegamos a compreender que esse "algo muito maior e indefinido" ao qual nossas obrigaçóes particulares remetem, se trata do próprio sentimento universal do dever; dever que, por sua vez, tanto costumamos considerar fundamentado em valores transcendentes - que nos seriam ensinados pelas religióes - quanto instituídos livremente pela própria humanidade. Por seu lado, Bergson nos propõe que, se bem refletirmos na força e na natureza desse sentimento de obrigação, o qual se encontra na memória mais remota e mais original da humanidade e de cada um de nós, compreenderemos que consiste em um hábito, e hábito social, justamente requerido, pela natureza, para a sobrevivência da espécie humana. É na sociedade, portanto, e não em uma ordem transcendente ou no próprio arbítrio humano, que Bergson fundamenta o dever e, consequentemente, a moral a ele ligada.

E o hábito social, o qual funda nossa moral, ganha sua força, ou seu caráter de obrigaçáo, que o faz diferente de qualquer outro hábito considerado individualmente, exatamente por refletir as determinaçóes naturais à espécie. É nessa medida que se compóe um todo, no qual cada parte retira sua força - o todo da obrigação. Com efeito, a espécie humana é menos obrigada a isso ou àquilo do que obrigada a ter uma obrigação, qualquer que seja ela, sendo, portanto, no interior dessa obrigação geral, apenas, que as obrigaçôes particulares ganham força. E é nessa medida ainda que, mesmo considerando a possibilidade de escolha - e o tipo de liberdade a ela ligada - como uma das características próprias à espécie humana, o 
hábito social humano, ou dever, pode ser comparado à necessidade das leis naturais que regem o comportamento das demais espécies vivas. $\mathrm{Na}$ verdade, Bergson, embora cuidadoso, procurando não ferir suscetibilidades - especialmente a dos filósofos que insistem na diferença entre "obrigação moral" e "necessidade natural" - parte de uma simples analogia entre as leis naturais (que regem os comportamentos sociais das demais espécies) e o hábito (que rege o comportamento social humano), para acabar assimilando a ambos, pois, no final das contas, não podemos fugir da noçáo de "ordem" que a ambos reveste. Bergson salienta: "Uma sociedade humana é um conjunto de homens livres. As obrigaçóes que ela impóe, e que lhe permite subsistir, introduzem nela uma regularidade que tem apenas uma analogia com a ordem inflexível dos fenômenos da vida. No entanto, tudo nos leva a crer que tal regularidade é assimilável a da natureza."( BERGSON, 2008a, p. 3-4). Independentemente da distinção entre necessidade e obrigação, defendida pelos filósofos e aceita pela maior parte da humanidade, "[...] a lei física, a lei social ou moral, toda lei, [...] é uma ordem.” (BERGSON, 2008a, p. 5). E isso porque, de um lado, como frisamos, a regularidade das leis da natureza não pode deixar de remeter à concepção de uma préordenação à qual os fatos parecem ter de "obedecer". Não é à toa, de resto, que concebemos a regularidade da natureza inscrita em "leis":

Há uma certa ordenação da natureza que se traduz por leis: os fatos "obedeceriam" a essas leis para se conformarem a essa ordem. [...] Mas, se a lei física tende a revestir, para a nossa imaginação, a forma de uma ordem, quando atinge certa generalidade, reciprocamente um imperativo que se dirige a todos se apresenta a nós um pouco como uma lei da natureza. (BERGSON, 2008a, p. 5) $)^{2}$

E será, portanto, também como obedecendo a uma lei que, de outro lado, pensamos o comportamento humano.

Mas não é verdade que justamente o que distingue a necessidade da natureza e a obrigação moral é o fato de podermos nos subtrair a esta e não àquela? Ao contrário dos indivíduos regidos pela necessidade das leis da natureza, não podemos desobedecer a um imperativo moral? O que conta aqui,

\footnotetext{
2 “O próprio cientista tem dificuldade em não acreditar que a lei 'preside' aos fatos e, consequentemente os precede, [...] deve travar uma verdadeira luta consigo mesmo para se representar os princípios da mecânica de outro modo que não como inscritos de toda a eternidade nas tábuas transcendentes que a ciência moderna teria ido buscar em um outro Sinai." (BERGSON, 2008a, p. 5).
} 
contudo, é menos a possibilidade de se subtrair a um imperativo moral e mais o fato de o próprio dever ser tomado universalmente como um imperativo. É esse dever universal que cai sobre nós como uma ordem à qual não se pode desobedecer. Ora, como defenderá Bergson, é possível se subtrair a um ou outro dever tomado individualmente, mas não ao próprio dever tomado em sua universalidade:

[...] cada um de nós, quando se volta para si mesmo, se sente livre para seguir seu gosto, seu desejo ou seu capricho, e não pensar nos outros homens. Mas basta o menor esboço de tal veleidade para que uma força antagonista, feita de todas as forças sociais acumuladas, sobrevenha; diferentemente dos móveis individuais, que atraem cada um para o seu lado, essa força chegaria a uma ordem que náo poderia deixar de guardar analogia com a dos fenômenos naturais. Uma célula que compóe um organismo e que se tornasse consciente por um instante, tão logo esboçasse a intenção de se emancipar seria assimilada pela necessidade. O indivíduo que faz parte da sociedade pode infletir e mesmo quebrar uma necessidade que imita àquela (a natural), uma necessidade que de algum modo ele ajudou a criar, mas que, sobretudo, ele sofre: o sentimento dessa necessidade, acompanhado da consciência de poder a ela se subtrair, não consiste menos no que ele [o indivíduo que faz parte da sociedade] chama de obrigação. (BERGSON, 2008, p. 5).

Ora, se a inteligência e o instinto são, para homens e animais (seres vivos inteligentes e instintivos) as capacidades segundo as quais tais espécies "funcionam" no sentido de garantir a sobrevivência de seus indivíduos, ambas capacidades - inteligência e instinto - o fazem segundo diferentes modos de utilizar instrumentos: "[...] aqui instrumentos inventados, consequentemente variáveis e imprevistos; lá órgãos fornecidos pela natureza e, consequentemente, imutáveis." E será exatamente a forma de organização que resulta dessa atividade variável, em um caso, invariável, em outro, que resultará no tipo de estabilidade das ações consideradas necessárias ou obrigatórias, na constituição de leis e na constituição do sentimento de obrigação.

Eis o ponto que nos concerne de perto. A variabilidade inerente à ação humana inteligente não permite que essas açôes sejam determinadas, como o são as açóes das formigas operárias, em um formigueiro, ou da abelha rainha, em uma colmeia. Estas são açóes especializadas, na medida da perfeita adequação existente entre elas e o corpo dos indivíduos que as executam. O corpo desses animais é o instrumento exato para a ação que cada um deles 
executa. Estabilidade e especialização das açóes que, de resto, se refletem também na estabilidade das relaçóes de coordenação e subordinação entre essas ações. No que diz respeito aos homens, entretanto, seu corpo não é especializado para nenhuma ação especifica, não é instrumento perfeitamente adaptado a nenhuma ação em particular, senão àquela mesma de fabricar outros instrumentos. Ora, se há variabilidade incontornável nas ações humanas e se, no entanto, para que a humanidade sobreviva, é preciso que essas açóes variáveis se coordenem e se subordinem entre si, isso só pode ocorrer se, nos homens, a necessidade não se encontrar na estabilidade desta ou daquela relação tomada particularmente, mas na existência mesma de relaçóes estáveis.

Em uma colmeia ou em um formigueiro, o indivíduo se fixa em sua função por sua estrutura e a organização é relativamente invariável, enquanto que na cidade humana ele o faz de modo invariável, aberto a todos os progressos. Disto se segue que, nas primeiras, cada regra é imposta pela natureza, ela é necessária; enquanto que nas outras, apenas uma coisa é natural, a necessidade mesma de uma regra. (BERGSON, 2008a, p. 22).

\section{SOCIEDADES FECHADAS E SOCIEDADES ABERTAS}

E é justamente essa necessidade que se equipara a um instinto virtual e que instaura o todo da obrigação que caracteriza o que Bergson chama de sociedades fechadas.

Vejamos um pouco mais de perto de que se trata.

Não importa que sejam sociedades humanas muito simples, ou sociedades recobertas pelas aquisições civilizatórias - conjuntos de hábitos e conhecimentos que, por mais vastos que sejam, continuam recobrindo um mesmo fundamento; primitivas ou civilizadas, as sociedades humanas saídas das mãos da natureza têm por essência abarcar um certo número de indivíduos e excluir outros, pelo que são chamadas, por Bergson (2008a, p. 25) de fechadas. Tais sociedades - de acordo com o princípio da coesão social, com vistas à sobrevivência, em que se fundamentam -, nunca dizem respeito à humanidade inteira e tampouco poderiam chegar a abarcar a humanidade por um movimento de ampliação. E isso se dá, justamente, na medida mesma em que é intrínseca a esse tipo de coesão a noção de exclusão, a qual, por sua vez, traduz a necessidade de ataque e de defesa. De fato, Bergson nos pede para percebermos que a exclusão e a defesa - eventualmente o ataque - são inerentes às sociedades fechadas; basta que consideremos o que ocorre, em tempos de 
guerra, com os valores do respeito à vida e à propriedade, os quais entendemos como fundamentais às sociedades e que reputamos abarcarem a humanidade inteira. Na guerra, sublinha Bergson, a "[...] morte e a pilhagem, a fraude e a mentira não apenas se tornam lícitas; são meritórias.” E ele nos pergunta: “Tal transformação se operaria tão fácil, geral e instantaneamente, se a atitude que a sociedade nos recomenda realmente dissesse respeito ao homem?" Ou seja, como é possível que tais valores possam ser tão prontamente abandonados? Não seria mais crível que eles não tenham sido abandonados, porque nunca, realmente, foram adotados, ao menos em relação a toda a humanidade? De resto, lembra ainda Bergson, de nada adiantaria, para tentarmos salvar o âmbito humano dos valores sociais, que considerássemos a guerra como um estado de exceção, no qual, portanto, valores normalmente válidos, e em relação a todos, fossem excepcionalmente suspensos e passassem a valer apenas para alguns. $\mathrm{O}$ fato, para Bergson, é que a exceção aqui é apenas aparente, ou um aspecto não menos normativo das sociedades; em outras palavras, ainda que as sociedades não vivam em guerra declarada, estão em constante estado de preparação para ela, porque "[...] a paz, até hoje, sempre foi uma preparação para a defesa ou para o ataque, de todo modo, para a guerra.” (BERGSON, 2008a, p. 27).

Assim, o estado de guerra declarada bem pode ser exceção, mas a preparaçáo para a guerra é norma, justamente porque as sociedades que saem das mãos da natureza são essencialmente a reunião de grupos que têm por objetivo a sobrevivência dos indivíduos que as compóem, ${ }^{3}$ constantemente colocada em risco por outros grupos e indivíduos, em constante hostilidade entre si. Dessa maneira, os grupos familiares fechados em si e virtualmente hostis entre si encontram o limite de sua extensão natural nas naçóes, na medida mesma em que a extensão dessas associaçóes não deve colocar em risco a própria possibilidade de associação. Famílias e naçôes são, portanto, agrupamentos sociais de mesma natureza, agrupamentos que se fecham em si, na medida mesma em que se defendem ou se atacam entre si, pois “[...] quem não vê", frisa Bergson (2008a, p. 28) “[...] que a coesão social se deve, em grande parte, à necessidade de uma sociedade se defender contra outras, e que é inicialmente contra todos os outros homens que amamos os homens

\footnotetext{
${ }^{3}$ Quanto à obrigaçáo, ou ao instinto virtual que se revela na indistinção entre o individual e o social que, de resto, é característica mesma da moral fechada, Bergson salienta: "Ora, é a esse instinto fundamental que relacionamos a obrigaçấo propriamente dita: ela implica, na origem, um estado de coisas no qual o individual e o social não se distinguem um do outro. Pelo que podemos dizer que a atitude à qual corresponde é a de um indivíduo e de uma sociedade voltados sobre si mesmos. Ao mesmo tempo individual e social, a alma aqui gira em círculo. Ela é fechada." (BERGSON, 2008a, p. 34).
} 
com quem vivemos?" Famílias e nações que, por sua vez, se encontram tão distantes da humanidade quanto o finito se encontra do indefinido, o fechado do aberto. Com efeito, a partir desse modo de associação - da família e da nação - não se passa, por nenhum tipo de ampliação, para a humanidade. Aqui é necessária uma ruptura, um salto, uma distinção de natureza, exatamente aquela pela qual se promove uma abertura no fechado, aquela pela qual se passa, ou melhor, se salta da sociedade fechada para a aberta, da moral fechada para a aberta.

\section{O SALTO}

Mas como se dá esse salto? Em que sentido ele é dado? Ou melhor, o que significa dizer que ele se dá de uma moral e sociedade fechadas para uma moral e sociedade abertas?

Em relação ao sentido do salto, podemos afirmar, desde já, que ele deve ser dado dessa situação de coesão interna a um grupo e de hostilidade externa entre grupos, fundada em relaçóes habituais, para uma situação em que a coesão não tenha como sua contraparte a hostilidade, ou a guerra. No que diz respeito às sociedades, a abertura deve se dar por meio de um salto que leve da "solidariedade social" à "fraternidade humana". Antes, no entanto, de nos estendermos na caracterização dessa "fraternidade humana" e no modo pelo qual ela se revela na ideia de justiça e, por extensão, na ideia de democracia que ora perseguimos, é importante refletir um pouco sobre a forma, ou a possibilidade mesma desse salto.

Inicialmente, devemos notar que esse salto ocorre por uma inversão no sentido de inserção da alma humana na própria natureza. De fato, lembremos que, desde os primeiros grupos até as grandes civilizaçóes, o homem se organiza socialmente segundo a dicotomia coesão/exclusão, justamente porque essa dicotomia reflete a maneira pela qual a inteligência conseguiu imprimir necessidade a essa mesma sociabilização. Ou seja, a sociabilização humana, ao ser definida pela inteligência, acompanha a característica mesma que define a humanidade e distingue essa espécie das demais; acompanha, portanto, a humanidade no sentido das determinaçóes que a fazem uma forma de vida entre outras; acompanha, por fim, esse sentido da natureza no qual o impulso de vida se detém e deposita formas de vida.

Levando isso em conta, a mudança de natureza na forma de sociabilização 
que vai das sociedades humanas fechadas para uma sociedade aberta, deve se dar, não em um aprofundamento ou fechamento da humanidade naquilo que lhe é próprio - nesse caso, nas características próprias à inteligência -, mas em uma aposta na inserção da humanidade no movimento de vida no qual ela foi gerada e do qual ela nunca se destacou totalmente, do qual ela ainda participa, em maior ou menor grau. Haveria, aqui, a necessidade de uma reflexão, a qual apenas indicaremos, que se aprofundasse naquilo que Bergson pensa a respeito dessa diferença, no sentido da inserção na natureza, das espécies, e de seus indivíduos. Em Evolução Criadora, com efeito, Bergson defende a hipótese de que o impulso de vida é um movimento criador que, todavia, é limitado. E caracteriza essa limitação como a interrupção do movimento criador que, nessa interrupçáo mesma, deposita o criado - as diferentes espécies e seus indivíduos. Ocorre que, se desse mesmo movimento criador que se interrompe decorre tanto uma inversão - uma vez que a vida, que é tensão, "fazer-se", decai no sentido da matéria inerte, da distensão, do desfazer-se - acontece também uma nova impulsão, porque novas formas de vida surgirão a partir das formas de vida gerada, pois a vida evolui pela evolução de suas formas de vida.

Retomemos, então. Se a espécie humana e sua sociabilização devem ser pensadas no âmbito da vida, no qual essa espécie vive e foi gerada, em que medida poderíamos pensar a abertura, ou evolução da espécie humana refletida nas formas em que ela se organiza socialmente, a partir dessa aposta da humanidade no movimento de evolução da vida, de sua inserção nesse sentido da vida?

Se se trata de progredir no impulso vital, relançando o movimento de criação a partir das formas de vida geradas por esse mesmo impulso, temos, aqui, de partir da inteligência. $\mathrm{E}$, aqui, mais uma questáo espinhosa, que apenas formularemos: seria a inteligência apenas uma "plataforma de salto"? Vejamos o que Bergson (2008a, p. 56) nos diz:

O homem, ao sair das mãos da natureza, sendo um homem inteligente e sociável, possui uma sociabilidade calculada para atingir pequenas sociedades, uma inteligência destinada a favorecer a vida individual e a vida em grupo. Mas a inteligência, dilatando-se por esforço próprio, atingiu um desenvolvimento inesperado. Libertou os homens das servidóes às quais ele estava condenado pelas limitaçôes de sua natureza. Nessas condiçóes, foi possível que alguns dentre eles, particularmente favorecidos, reabrissem o que tinha sido fechado e fizessem, ao menos para si mesmos, aquilo que a natureza náo pode fazer para toda a humanidade. Exemplo que acabou atraindo os demais, ao menos em imaginação. 
Aqui a inteligência parece ser, portanto, a condição que faculta a evoluçáo, a condição que faculta a abertura da espécie para que esta transcenda às determinaçôes que a constituem, mas que não constitui, ela mesma, essa abertura. Mas como esse processo se daria, efetivamente? A crer nas palavras de Bergson acima citadas, por uma dilatação e desenvolvimento da própria inteligência. Dilatação e desenvolvimento que, como sabemos, advertidos pelos sentidos que esses termos ganharam, em Evolução Criadora, significam tanto o despertar das "[...] virtualidades da intuição que nela ainda dormitam" (BERGSON, 2008b, p. 197) - o que, de algum modo, já tocaria na nova natureza que aqui se quer compreender - quanto um desenvolvimento da inteligência que significa um maior domínio da matéria, para nos livrar do jugo por ela exercido sobre nós. Liberação do jugo da matéria que, por sua vez, teria consequências muito mais importantes do que aquelas vantagens que podem ser auferidas imediatamente dos objetos fabricados. Conforme assinala Bergson, tal vantagem, embora seja o que o inventor procura, “[...] é pouca coisa perto das ideias novas, dos sentimentos novos que a invenção pode fazer surgir de todos os lados, como se tivesse por efeito essencial nos lançar acima de nós mesmos e, ao fazê-lo, ampliar nossos horizontes." (BERGSON, 2008b, p. 198) Verdadeira desproporção, constatada por Bergson, entre a causa e o efeito da atividade inteligente que o leva a cogitar se o domínio da matéria pela inteligência não teria por alvo principal deixar passar o movimento de vida ali aprisionado (BERGSON, 2008b, p. 198).

Desproporção que Bergson procura concretizar pelo exemplo da diferença entre a situação da criança ocupada em manipular uma máquina a vapor primitiva e aquela que inventa um mecanismo pelo qual a máquina passa a funcionar sozinha; mecanismo que, de resto, se resume à coordenação dos movimentos da máquina por um barbante amarrado a algumas de suas peças. Entre as máquinas, nada mais há do que uma "[...] ligeira diferença de complicação", contudo, sublinha Bergson, basta um lance de olhos na direção das crianças para perceber a radical diferença entre elas: "[...] uma está absorvida na vigilância, [...] a outra está livre para divertir-se a seu belprazer", uma mantém sua "atenção cativa”, a outra tem sua atenção liberada. Desproporção entre a causa - uma pequena diferença de mecanismo, uma simples invenção da inteligência - e seu efeito - a liberação da atenção.

Seria, portanto, para essa liberação da atenção que os próprios mecanismos inteligentes, ou a própria inteligência, teria sido gerada pelo movimento próprio à vida? Possibilidade plausível, se levarmos em consideração 
que toda a intenção da vida consiste em se perpetuar, perpetuação que tem de se haver com seus limites, a própria matéria, e perpetuação que, de resto, nem sempre alcança sucesso por todos os caminhos em que é buscada, como nos mostram os "becos sem saída" que constituem muitas das formas de vida geradas.

Mas voltemos às consequências, para o nosso tema, dessa breve retomada do pensamento bergsoniano sobre o movimento da vida, ou seja, voltemos para o modo pelo qual as espécies, mais especificamente, a espécie humana, pode, no que concerne à sua organização em sociedade, romper o círculo das determinaçóes que a constitui e saltar no sentido da criação.

Bergson nos dizia que esse rompimento e consequente salto se dá pela passagem da "solidariedade social" à "fraternidade humana", o que justamente seria facultado pela ampliação e desenvolvimento da inteligência, nos sentidos apresentados acima. Ocorre, no entanto, que tal rompimento só se concretizaria em alguns indivíduos privilegiados da espécie. Indivíduos que, liberados pela inteligência foram, contudo, além dela - não apenas inventaram, mas também criaram -, e indivíduos que, com suas criaçóes, exerceriam uma atração sobre os demais, se colocariam como exemplos, ideais aos quais os demais aspirariam. Atração que, nesse sentido, nada mais seria do que a atração "natural" ao próprio movimento da vida personificado em alguns indivíduos e exercida sobre aqueles outros indivíduos em condições de receber esse apelo.

\section{ENTRE A PARALISIA E O SALTO: O COLOCAR-SE EM MOVIMENTO}

Não nos concentremos, no entanto, nestes homens privilegiados que exercem atração sobre os demais e, sim, naqueles que sofrem esta atração, na grande maioria dos homens que, tendo desenvolvido sua inteligência, são capazes de criticar a moral fechada do hábito e, tendo ampliado sua inteligência no sentido do despertar da intuiçáo - mesmo náo a tendo despertado suficientemente, para dar o salto que cria novos valores -, são capazes de reconhecer e se deixar atrair pelos novos valores criados e apresentados pelos "novos homens".

Com efeito, Bergson chama a moral das almas fechadas, regidas pelo instinto virtual, de moral infra-intelectual; a moral das almas que já se abriram para o novo, de moral supra-intelectual; e a moral dessas almas que se abrem 
para o novo, ou que se deixam atrair para o movimento que leva a ele, de moral intelectual.

Entre a alma fechada e a alma aberta há a alma que se abre. Entre a imobilidade do homem que está sentado e o movimento do mesmo homem que está correndo, há o aprumar-se, a atitude que ele assume quando se levanta. Em resumo, entre o estático e o dinâmico observamos uma moral de transiçáo. (BERGSON, 2008a, p. 62).

Esta tanto pode ser caracterizada pela moral contemplativa do filósofos gregos, ${ }^{4}$ quanto pela situaçáo em que se encontra, de fato, cada um de nós, seres inteligentes, na medida mesma em que as forças de impulsão e de atração aqui caracterizadas se exercem em conjunto sobre nós e, em nós, são manipuladas pela inteligência.

Para refletir sobre esse misto de impulsão e atração, manipulado pela inteligência, o qual marcaria a moral de transição por nós vivida, Bergson toma a noçáo de justiça - que ele considera a mais instrutiva, "[...] porque engloba a maior parte das demais, [...] se traduz, apesar de sua maior riqueza, por fórmulas simples, [...] e sobretudo porque nela vemos sobreporem-se, uma sobre a outra, as duas formas de obrigação".

Bergson inicia sua reflexão sobre seu exemplo modelar, remontando aos seus sentidos mais longínquos, mais originais, a saber, as ideias de equidade, de proporção, de compensação, sentidos todos próprios ao contexto de trocas - tanto no que se refere às coisas quanto às relaçôes entre pessoas e grupos -, nos quais os homens se veem envolvidos, desde sua mais remota história ${ }^{5}$ e que, por si só, indicam o caráter relativo desta justiça. Não parece ser à toa que essa justiça relativa seja representada por uma balança e que sua máxima seja a lei de talião - "olho por olho, dente por dente" -, máxima pela qual se prevê certa equidade, certa proporçáo ou reciprocidade entre crime e castigo, entre ofensa recebida e reparação.

Haveria, no entanto, uma noção de justiça não relativa, aquela que, justamente, se funda na noção de incomensurabilidade e de inviolabilidade,

\footnotetext{
4 "Em relação àquilo que ela acaba de deixar para trás, tal alma praticaria a indiferença ou a insensibilidade; ela estaria na 'ataraxia' ou na 'apatia' dos epicuristas e dos estoicos. Em relação àquilo que ela encontra de positivo nela, se seu desligamento do antigo quer ser uma uniáo com o novo, sua vida seria contemplação; ela se conformaria ao ideal de Platão e de Aristóteles." (BERGSON, 2008a, p. 63.
}

${ }^{5}$ Ver, a esse respeito, as análises desenvolvidas em Bergson (2008a, p. 69ss). 
aquela que, como enfatiza Bergson, é a "[...] afirmação pura e simples de um direito inviolável e da incomensurabilidade entre a pessoa e todos os valores."( BERGSON, 2008a, p. 71). Essa moral absoluta, se ela existe, ainda que, para uma maioria, apenas como ideal, foi intuída, ou, o que é o mesmo para Bergson, criada, a partir de determinadas situaçóes imprevisíveis e por meio da própria imprevisibilidade introduzida por algumas, ou mesmo, por uma pessoa. Em suma, essa justiça nova, e absoluta, porque não se funda na ideia de relaçáo, não poderia ser considerada como o simples desenvolvimento da justiça relativa anterior. Ao invés de estar dada desde sempre e de sofrer aproximaçôes - ou degradaçôes - contínuas; ao invés de ser um ideal do qual nos aproximaríamos gradualmente, por meio de visóes parciais, a nova justiça transfigurou a antiga, alterou o antigo do seu interior, "[...] tomou o antigo para englobá-lo em um todo imprevisível”, ${ }^{6}$ e "[...] de uma só vez, em um determinado momento, por um salto brusco."

Donde voltamos à questáo anterior, agora relativa às duas formas de justiça e anteriormente colocadas em relaçáo às duas formas de moral: como se dá o salto entre uma e outra. Mas donde voltamos, também, à questão que aqui queremos privilegiar, a saber, à questão sobre como é possível esse estado entre uma e outra justiça, estado misto em que, uma vez concebida, esta nova justiça não se realiza, mas permanece como um ideal.

Questáo que diz respeito, portanto, ao "aprumar-se", referido acima, aprumar-se para colocar-se em movimento no sentido de algo a que se aspira. Questão cujo tratamento podemos perseguir precisamente quando Bergson trata dos regimes nos quais estas diferentes ideias de justiça vigoram. De um lado, os regimes que se fundam na justiça entendida enquanto sistema de compensações, na qual os próprios homens são medidos em relação a certos valores estabelecidos como critérios dessa medição; de outro lado, o regime no qual a pessoa (ou seja, todos os homens) tem valor incomensurável e, portanto, regime no qual é na pessoa que todo e qualquer valor se funda e se legitima. Tratemos, finalmente, dos regimes oligárquicos e das democracias, ou, do estado misto entre um e outro.

\footnotetext{
${ }^{6}$ Impossível não remeter essa passagem às críticas frequentes feitas por Bergson ao preconceito, do ponto de vista analítico, e sua substituição pelo pensamento em duração. Ver, a esse respeito, Bergson (2008a, p. 71ss).
} 


\section{ENTRE A OLIGARQUIA E A DEMOCRACIA}

Vejamos primeiramente o que Bergson nos diz sobre a oligarquia.

Antes de apresentá-la, ele reitera a ideia, referida acima, de que esse regime deve ser procurado em uma sociedade completa, embora primitiva, ou seja, em uma sociedade "[...] capaz de se defender e, consequentemente, por menor que ela seja, organizada para a guerra."(BERGSON, 2008a, p. 78, 295). Isso posto, Bergson observa que tais regimes, oligárquicos ou monárquicos, são aqueles que mantêm a coesão, requerida pela natureza, por meio de uma relação de mando e obediência, a qual, por sua vez, é garantida, não mais por um polimorfismo físico, como nos insetos - nos quais a diversidade das funçôes sociais se relaciona com uma diferença de organização - mas, no caso humano, por um "dimorfismo" psíquico. O que isso quer dizer? Para que a coesão nas sociedades humanas fechadas seja garantida com algo análogo à conformação morfológica e ao instinto nos animais, para que essa coesão seja, portanto, garantida necessariamente, ela se funda em uma predisposição humana a obedecer e a mandar. Não, acrescenta Bergson, no modo como Nietzsche concebeu essas disposiçóes, como distribuídas entre os homens, pelo que determinados homens seriam predispostos a serem chefes e outros escravos. Para Bergson, tal dimorfismo estaria presente em cada alma humana e faria "[...] de cada um de nós, ao mesmo tempo, um chefe que tem o instinto de comandar e um subjugado pronto a obedecer, ainda que a segunda tendência domine a ponto de aparecer sozinha na maior parte dos homens." (BERGSON, 2008a, p. 296). De resto, é o que parece poder ser confirmado, nas épocas revolucionárias, pela revelação de grandes lideranças em homens anteriormente modestos e obedientes, homens servis que se tornam líderes, quase sempre implacáveis, pois, mais uma vez, a natureza não pode dar espaço à deliberação humana, quando o que está em jogo é a sobrevivência de uma sociedade diante do virtual ataque de outra. Ora, nesses regimes sociais de chefes e subordinados, de líderes e liderados, tanto o comando quanto a obediência devem ser absolutos.

É assim que, indo no sentido contrário ao desses regimes oligárquicos que saem das mãos da natureza, e cuja coesão é originalmente fundada na subordinação pela força, ou, no máximo, em uma justiça relativa, surge a concepção política que "[...] mais se distancia da natureza, a única que transcende, ao menos em intenção, as condiçôes da 'sociedade fechada" (BERGSON, 2008a, p. 78 e 299), a concepção política fundada na criação dos "direitos do homem", trazida pelo ideal da justiça absoluta, a concepção 
política que os modernos chamamos de democracia. ${ }^{7}$ Aqui não há mais a relativização de direitos pela "posição" - leia-se supostos valores ou serviços prestados - de um grupo entre outros ou de indivíduos, no interior de um mesmo grupo. Há os direitos do homem que, assim como foram declarados pelos americanos, em 1776, pelos revolucionários franceses, em 1791, e por todas as declaraçóes posteriores às quais estas serviram de modelo, "[...] não mais evocam ideias de relação ou de medida, mas, ao contrário, de incomensurabilidade e de absoluto"; nelas, os direitos são considerados “naturais, inalienáveis e sagrados”. (BERGSON, 2008a, p. 299). Não há mais dominados e dominadores, pois o direito, agora, é aquele mesmo de criar direitos e, assim fazendo, aspirar à sua realizaçáo, convertê-lo em dever; o direito, agora, é o de ser, ao mesmo tempo, aquele que se dá a lei e que a ela se submete. Referência explícita a Kant que, no entanto, deve se resguardar de escorregar para qualquer tipo de intelectualismo. Aqui, se há lei, propriamente dita, ela só pode ser a tentativa indefinida e sempre incompleta de instaurar um sentimento que vai além dela, sentimento que, só ele, e não qualquer razão ou conjunto de razões, pode ser seu fundamento. Aqui, por conseguinte, conforme assinala Bergson (2008a, p. 300), “[...] o conjunto de cidadãos, quer dizer, o povo, é soberano. Tal é a democracia teórica. Ela proclama a liberdade, reclama a igualdade e reconcilia essas duas irmâs inimigas colocando acima de tudo a fraternidade."

Nesse ponto, Bergson marca posição contra as críticas ao caráter "natural" desses direitos, por interpretaçôes que lhe dariam um fundamento racionalista ou histórico. De fato, ele denuncia, em vários momentos do texto, a impossibilidade de a razão tanto se estabelecer como fundamento desses direitos inalienáveis e sagrados quanto de mobilizar o homem no sentido de sua realização (BERGSON, 2008a, p. 85ss.) Mas ele também critica a tentativa de reduzir a criação aqui envolvida, quer a criação dos direitos do homem, quer a do regime que busca concretizá-los, a democracia, ao simples resultado de um processo histórico, uma realização que se daria por si mesma, "[...] pouco a pouco, em virtude do estado de alma da sociedade em um determinado período de sua história." (BERGSON, 2008a, p. 74).

\footnotetext{
${ }^{7}$ Bergson considera que a humanidade chega à democracia, ou, ao menos, ao seu ideal, apenas tardiamente, uma vez que não considera a possibilidade de sociedades verdadeiramente democráticas se fundarem em sistemas escravocratas: "Compreendemos que a humanidade só chegou à democracia tardiamente (pois as das cidades antigas eram falsas democracias, construídas sobre a escravidão, livrando-se por essa iniquidade fundamental dos maiores e mais angustiantes problemas)." (BERGSON, 2008a, p. 299).
} 
$\mathrm{Na}$ verdade, o aparente paradoxo que, de resto, acompanha toda a filosofia da duração, é justamente o de pensar o absoluto continuamente criado no âmbito do devir. Absoluto, por ser aquilo que encontra seu valor em si mesmo e não em qualquer tipo de comparação com o outro, por meio de uma medida exterior a ambos e, portanto, aquilo que, por náo se relacionar nesse sentido com nada mais do que consigo mesmo, é a própria expressão do novo. Criado no âmbito do devir, porque tanto surge das contingências próprias ao devir quanto se relaciona com determinados indivíduos situados nesse devir. Isso posto, topamos novamente com nossa insistente questáo anterior: como pensar o surgimento do absolutamente novo, no interior de um processo contínuo? Que tipo de descontinuidade, salto, criação, pode haver no contínuo? E, aqui, são as antigas reflexôes sobre a duração que voltam e têm de voltar. De fato, queremos crer que, para Bergson, a duração não se dá por si mesma, ela acontece pela tensão de uma vontade, e é pela tensão da vontade que, em um determinado momento, ocorre a transformaçáo radical de tudo o que foi sendo continuamente conservado. Mas tensão da vontade que, no entanto, encontra seus limites, estaciona e retrocede em repetição.

É assim que, como vimos, Bergson também concebe a evolução da vida, inicialmente como um impulso criativo, um movimento progressivo de criação, o qual, por sua própria finitude, se interrompe e, ao se interromper, dá origem às espécies ao mesmo tempo em que surge o sentido contrário ao da criação, o sentido do movimento regressivo, da matéria, da repetição, pois, citando novamente Canguilhem (2007), para Bergson, a interrupção do movimento criador significa inversão. Todavia, mesmo finito, o movimento da vida não se extingue. Para Bergson, isso se explica justamente porque o sentido progressivo do movimento de vida é sempre retomado, do interior de cada espécie, por um esforço que, agora, tem de ir contra o sentido regressivo no qual cada espécie está instalada. Tal retomada depende, portanto, de um esforço, de um retensionamento da vontade, ou das vontades implicadas nesse processo, que retome o sentido original de criação contra o sentido no qual cada espécie está instalada e que já é o da degeneração. Se é assim com a evolução da vida, também é assim com a evolução própria ao homem, sua história. E, por conseguinte, eis nossa segunda questão, a questão que privilegiamos: como induzir o resultado dessa extrema concentração da vontade, no âmbito mesmo da sociedade humana?

Dessa maneira, considerando o devir próprio ao homem, sua história, Bergson também entende que ela não decorre de si mesma, ou do simples 
desenvolvimento de um princípio que lhe seria interior, mas transcorre pelo tensionamento das vontades nela inseridas, a partir das contingências que vão sendo nela geradas. Criado no movimento progressivo da vida, enquanto forma específica de vida, o homem também instaura o sentido regressivo desse movimento, fixando-se na forma de existência determinada pela forma de vida que ele é. Ocorre que nele persiste o impulso criador de vida do qual surgiu e, mais, sua própria especificidade, a inteligência, parece auxiliá-lo na liberação desse impulso. De qualquer modo, o homem constrói sua história pela manipulação constante de sua tendência regressiva e progressiva, ou seja, de sua tendência a curvar-se às determinações da espécie e sua tendência a transcendê-las, produzindo o novo, criando novas formas de existência. Queremos chamar a isso dialética? Apenas se aqui compreendermos a dialética em um sentido bastante específico, a saber, aquele que admita que a origem do movimento de progressão e regressão está na vontade e produz verdadeira novidade.

De fato, enfatiza Bergson, quando há criação e, especificamente, no caso da criação dos direitos absolutos do homem que fundamentam os regimes democráticos, "[...] trata-se de um salto para frente, que só acontece se a sociedade se decidiu a tentar uma experiência” ainda que, para tanto, seja preciso "que ela se deixe convencer ou, ao menos, abalar; abalo que sempre é feito por alguém.”(BERGSON, 2008a, p. 74).

\section{O MÉTODO}

Assim como na arte, frisa Bergson, aqui se trata de tomar um estado de alma como realizado para instigar a sua realizaçáo. Ora, não seria justamente isso o que o artista faz, quando cria uma obra genial? Aposta na compreensão, pela sociedade, da novidade que ele está propondo, quando é essa própria novidade, a depender de sua força, quem vai gerar o estado de alma capaz de aceitá-la, fazê-la ser considerada uma obra de arte e não apenas uma obra desconcertante. Trata-se do "milagre da arte", conforme assevera Bergson: "[...] criar pouco a pouco, simplesmente por sua presença, uma concepçáo de arte e uma atmosfera artística que permitirão compreendêla."( BERGSON, 2008a, p. 75). Trata-se do milagre, realizado por algumas almas privilegiadas, da quebra do círculo das repetiçóes pelo que, assim como o novo padrão estético, se criaria um novo padrão moral.

O mesmo método deve, por conseguinte, aplicar-se à moral. Nas 
palavras de Bergson (2008a, p. 78):

Método que consistiria em supor como possível o que é efetivamente impossível em uma determinada sociedade, em se representar o que resultaria disso para a alma social, e em induzir, então, algo desse estado de alma pela propaganda e pelo exemplo. O efeito, uma vez obtido, completaria retroativamente sua causa; sentimentos novos, de resto evanescentes, suscitariam a nova legislação que pareceria necessária ao seu aparecimento e que serviria, então, para sua consolidação.

Como utilizar tal método, para passar da oligarquia à democracia? É uma pergunta que equivale, para Bergson, às anteriores: como passar da sociedade fechada para uma sociedade aberta, como passar da justiça relativa para a justiça absoluta? $\mathrm{Ou}$, ainda, segundo a perspectiva que aqui privilegiamos, como, ao menos, manter a passagem aberta? E, aqui, as reflexôes realmente se encontram. Tanto no primeiro capítulo de As Duas Fontes quanto no último, é da passagem a um regime de classes privilegiadas e opressoras para um regime no qual o povo, ou melhor diríamos, o homem, na figura do povo, é soberano que se trata. E a conclusão é sempre a mesma:

A ideia moderna de justiça progrediu [...] por uma série de criaçóes individuais que obtiveram sucesso por múltiplos esforços animados por um mesmo elā. [...] E isto não é verdade apenas em relação à justiça, mas também em relação àquilo que se coordena com ela, igualdade e liberdade, por exemplo. (BERGSON, 2008a, p. 79).

De fato, continua Bergson, é pelo encaminhamento no sentido da liberdade e da igualdade que costumamos avaliar o progresso da justiça, ainda que essa avaliação nos sirva apenas para tratar do passado e nada nos diga sobre as realizações futuras e o encaminhamento para elas.

Voltemos, pois, aos valores acima referidos e que compóem a divisa republicana, as sociedades que consideramos justas, a democracia: liberdade, igualdade e fraternidade.

$\mathrm{Na}$ verdade, as leis criadas pela sociedade no sentido de garantir a realização da liberdade e da igualdade são apenas esquemas, exteriorizaçóes da liberdade e da igualdade criadas por alguns dentre nós, como direitos inalienáveis de todos os homens. Tais leis teriam, portanto, menos a capacidade de instaurar a liberdade e a igualdade do que suscitar em nós o estado de alma 
requerido para que elas realmente fossem instauradas. De resto, como esse processo de instauraçáo seria dinâmico e como a maioria de nós vive apenas no registro da lei, da fórmula, segue-se que, no registro mesmo da lei, os direitos da liberdade e da igualdade aparentemente disputam entre si.

Tomemos a noção de liberdade. Ela não se expressa na formulação canônica, presente na Declaração dos Direitos do homem, segundo a qual "[...] o indivíduo tem direito a toda liberdade que não lese a liberdade do outro"? (BERGSON, 2008a, p. 80). Tal formulação, se tem o objetivo de se opor aos arbítrios exercidos contra a inviolabilidade da pessoa, de se opor ao exercício da autoridade exterior à pessoa e, assim, quebrar o exercício de sua vontade, por outro lado, náo acabaria por nos levar a um individualismo que ameaça a própria democracia? ${ }^{8}$

Assim, não poderíamos nos perguntar, com Bergson (2008a, p. 80), se

[...] a concepção de uma nova liberdade que tivesse por consequência, na sociedade atual, uma sobreposição de todas as liberdades umas sobre as outras, poderia produzir o efeito contrário em uma sociedade na qual esta reforma tivesse modificado os sentimentos e os costumes. De modo que é quase sempre impossível dizer a priori qual é a dose de liberdade que podemos conceder ao indivíduo sem prejuízo para a liberdade de seus semelhantes: quando a quantidade se modifica, não se trata mais da mesma qualidade.

Considerações semelhantes poderiam ser feitas em relação à igualdade. De fato, não é comum vermos regimes ditos democráticos criticarem ou mesmo cercearem ferozmente sua ampliação em nome da liberdade? Mas, de que igualdade essas democracias falam? Da igualdade de direitos políticos, de condiçốes sociais, de condiçốes econômicas, de propriedade etc.? Qual dessas liberdades coloca em risco a liberdade? Alguma delas efetivamente o faz? Ou, se o faz, ela o faz com que direito?

Sem desenvolver esse ponto que, acredito, merece uma nova abordagem da questão das relaçóes entre a moral e a política em Bergson, fiquemos, por ora, com as indicaçóes do próprio Bergson (2008a, p. 80):

\footnotetext{
${ }^{8}$ Talvez exatamente por fundar-se em uma concepção equivocada de pessoa que confunde um todo dinâmico e em relação profunda com tudo o que vive, com um indivíduo absolutamente destacado dos demais e de tudo a sua volta?
} 
Por outro lado, a igualdade só se obtém às expensas da liberdade, de modo que será preciso começar se perguntando qual das duas é preferível. Mas essa questáo não comporta nenhuma resposta geral; pois o sacrifício dessa ou daquela liberdade, se é consentido pelo conjunto dos cidadãos, ainda é liberdade; e, sobretudo, a liberdade que restar poderá ainda ser de uma qualidade superior se a reforma realizada no sentido da igualdade resultou em uma sociedade na qual respiramos melhor, na qual encontramos mais alegria em agir [...].

\section{E com sua conclusão:}

Como pedir uma definição precisa da liberdade e da igualdade, quando o futuro deve estar aberto a todos os progressos, notadamente à criação de novas condiçôes nas quais se tornarão possíveis formas de liberdade e de igualdade hoje irrealizáveis, talvez mesmo inconcebíveis? Só podemos traçar esquemas, que se preencherão na medida em que a fraternidade neles se realizar. [...] Se tomarmos a divisa republicana (liberdade, igualdade, fraternidade) sob este ponto de vista, perceberemos que este terceiro termo suspende a contradição tão frequentemente enfatizada entre as outras duas, e que a fraternidade é essencial: o que permitiria dizer que a democracia é de essência evangélica [...]. (BERGSON, 2008a, p.300-301).

A liberdade e a igualdade, assim como nos foram criadas por aqueles que as criaram e as propuseram a nós, só podem ser realizadas pela fraternidade, na medida mesma em que a fraternidade é sua reinserção no dinâmico, a reinserção no movimento mesmo no qual elas foram criadas e no qual elas não entram em contradição. Não é à toa que Bergson, ao nos apresentar o que seria a fórmula de um regime náo democrático pela oposição à formula da democracia, opóe fraternidade à fixidez, de modo que, no lugar de "[...] liberdade, igualdade e fraternidade" teríamos "autoridade, hierarquia e fixidez”. (BERGSON, 2008a, p. 301).

No entanto, a realização da liberdade e da igualdade em caráter absoluto só pode ser encaminhada, relativamente, por meio das leis, ou, se quisermos, pelo âmbito jurídico que, ao se manter exterior a esses direitos, mais diz a que eles se opóem do que aquilo que realmente propóem. É assim ainda que, se as leis e declaraçôes são vagas quanto ao caráter positivo dos direitos democráticos, registram mais objetivamente a resistência àquilo de que se quer separar-se. Donde o caráter de oposição aos vários tipos de opressão, o tom de desafio contra abusos sofridos próprios a cada um dos 
artigos da Declaração dos Direitos do homem. Bergson nos conta, a esse propósito, que Émile Faguet, ao resumir as demandas apresentadas aos Estados Gerais, teria escrito que a Revolução não foi feita pela liberdade e pela igualdade, mas porque se morria de fome. Ora, se assim for, observa Bergson (2008a, p. 301), teríamos então de nos perguntar por que, em um determinado momento, não se aceita mais passar fome. Com efeito, parece não ser possível separar o conteúdo mesmo dos direitos, sempre positivos, e a negatividade pela qual eles se expressam, a saber, pela formulação jurídica daquilo a que se opõem. Se, realmente, a Revolução foi feita para que não mais se morresse de fome, e a Declaração que a objetiva é clara em relação ao que interdita, é porque não mais se admite morrer de fome, é porque se interditam abusos desse tipo e, isto, em nome do valor positivo e absoluto assumido por cada pessoa. "A intenção com a qual uma ideia é lançada, permanece aderente a ela nos diz Bergson, como a direção a uma seta [...] as fórmulas de democráticas, enunciadas inicialmente em um pensamento de protesto, pressentem-se de sua origem." Em Bergson (2008a), de fato, a criação está ali, sempre original, sempre a dirigir a reação, a resistência, ainda que também sempre esteja presente o perigo de que sua transposição, nas fórmulas relativas, promova uma tal inversão em seu sentido original que não mais seja possível voltar a ele. ${ }^{9} \mathrm{O}$ original é positivo, é impulso, movimento progressivo, é criação, mas impulso limitado que produz o seu próprio negativo, a partir do qual ele deve ser novamente relançado. E aí se encontra um risco, o risco de que o negativo se superponha à criação.

CAPPELLO, Maria Adriana Camargo. Democracy in The Two Sources of Morality and Religion: resistance and aspiration. Trans/form/ação, Marília, v. 40, n. 2, p. 139-162, Abr./ Jun., 2017.

\begin{abstract}
This article reflects on the conception of democracy presented by Bergson in The Two Sources of Morality and Religion. Democracy is there conceived as a human and social movement of resistance and aspiration in the context of a theory of life; and life is itself conceived as a movement that takes place in two senses, that of determination and that of creation.
\end{abstract}

Keywords: Bergson. Morality. Politics. Democracy. Evolution. Creation. Determination

\footnotetext{
${ }^{9}$ De fato, para Bergson, o perigo do fechamento, representado pelos interesses particulares e de grupo, sempre ronda o movimento de abertura que abarcaria toda a humanidade e, sendo assim, as leis, que deveriam assegurar os direitos do homem, sempre podem ser infletidas no sentido contrário ao de seu espírito.
} 
CAPPEllO, M. A. C.

\section{REFERÊNCIAS}

BERGSON, H. Les deux sources de la morale et de la religion. Paris: PUF, 2008a.

BERGSON, H. L'évolution créatrice. Paris: PUF, 2008b.

CANGUILHEM, G. Commentaire au chapitre 3 de L'évolution créatrice de Bergson. In: WORMS, F. (Ed.) Annales Bergsoniennes III. Paris: PUF, 2007. p. 113-160.

Recebido em 03/02/2017

Aceito em 27/02/2017 